\title{
Current Status of Bacillus thuringiensis for Spruce Budworm Control
}

\author{
by
}

\author{
M.A. Hulme1, T.J. Ennis², and A. Lavallée ${ }^{3}$
}

\begin{abstract}
Research and development over many years have now established that Bacillus thuringiensis Berliner (B.t.) can be a safe and effective biological insecticide for spruce budworm. B.t. must be ingested before it can kill the insect and good results are thus obtained when the B.t. spray is applied at the correct time and covers the foliage so that most larvae consume a lethal dose of B.t. within 1 or 2 days of application. Under these conditions, B.t. treatments can save as much foliage as chemical insecticide treatments. However, the cost of materials and application for a B.t. treatment is higher than for a chemical treatment. In recent years emphasis in B.t. research has thus been to reduce cost by obtaining better distribution of the material on foliage, by reducing the volume of liquid carrier, and by looking for strains and fermentations of B.t. that provide an even more potent product against spruce budworm.
\end{abstract}

Résumé

Les nombreuses années de R\&D ont permis d'établir que Bacillus thuringiensis Berliner (B.t.) constitue un agent efficace et sans danger de répression biologique de la tordeuse des bourgeons de l'épinette. Le B.t. doit être ingéré par l'insecte pour le tuer. On obtient de bons résultats lorsque les pulvérisations sont effectuées au moment approprié et lorsque le dépôt sur le feuillage est tel que la plupart des larves ingèrent une dose létale au cours des deux premiers jours suivant l'arrosage. Lorsque ces conditions sont remplies, le B.t. peut apporter une protection du feuillage aussi bonne que les insecticides chimiques. Toutefois, le coût du traitement, incluant matériel et arrosage, est plus éléve. Le principal objectif des recherches sur B.t. est de réduire les coûts par une meilleure répartition du produit sur le feuillage, par une diminution du volume du support liquide et par l'emploi de souches et de fermentations de B.t. qui donneraient un produit encore plus efficace contre la tordeuse.

\section{Introduction}

Bacillus thuringiensis Berliner is a naturally occurring bacterium that can cause fatal diseases in certain insects. It was first isolated in 1905 from dying silkworm larvae and in 1911 , Berliner, a German entomologist working in Thuringia, isolated the bacterium from diseased Mediterranean flour moths. The bacterium is classified as a Bacillus because of its appearance and activity and is thus named Bacillus thuringiensis Berliner. This is commonly abbreviated to B.t.

Besides producing a spore, which allows the organism to survive in a dormant state, B.t. simultaneously produces a proteinaceous crystal (Fig. 1). Many larvae of butterflies and moths die if they ingest the spores and crystals of the bacterium (Fig. 2), and the possibility of controlling certain insects with B.t. was recognized many years ago. Indeed, a product called Sporeine was produced commercially before 1938 .

1 Pacific Forest Research Centre, Victoria,

2 Forest Pest Management Institute, Sault Ste. Marie

${ }^{3}$ Centre de recherches forestières des Laurentides, Québec.
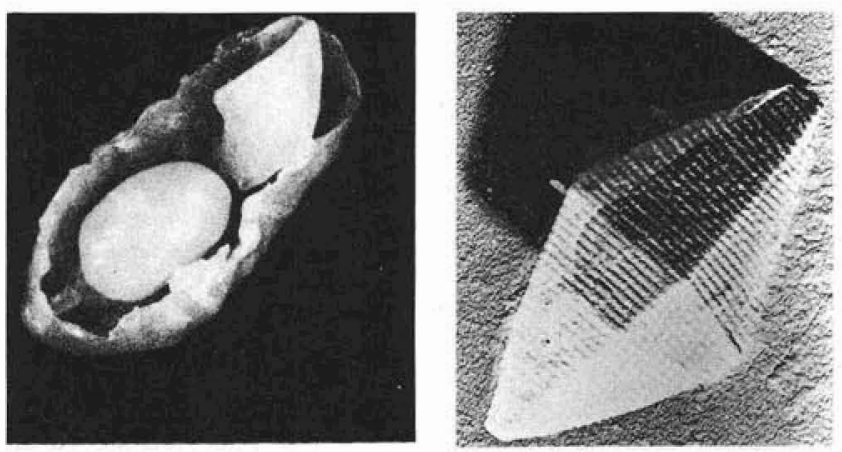

Figure 1. (a) Spore and crystal produced within a cell (broken outer casing shown) of Bacillis thuringiensis. Photo courtesy Centre de recherches forestières des Laurentides. (b) Enlarged view of $B$. thuringiensis crystal. Photo courtesy Forest Pest Management Institute. 


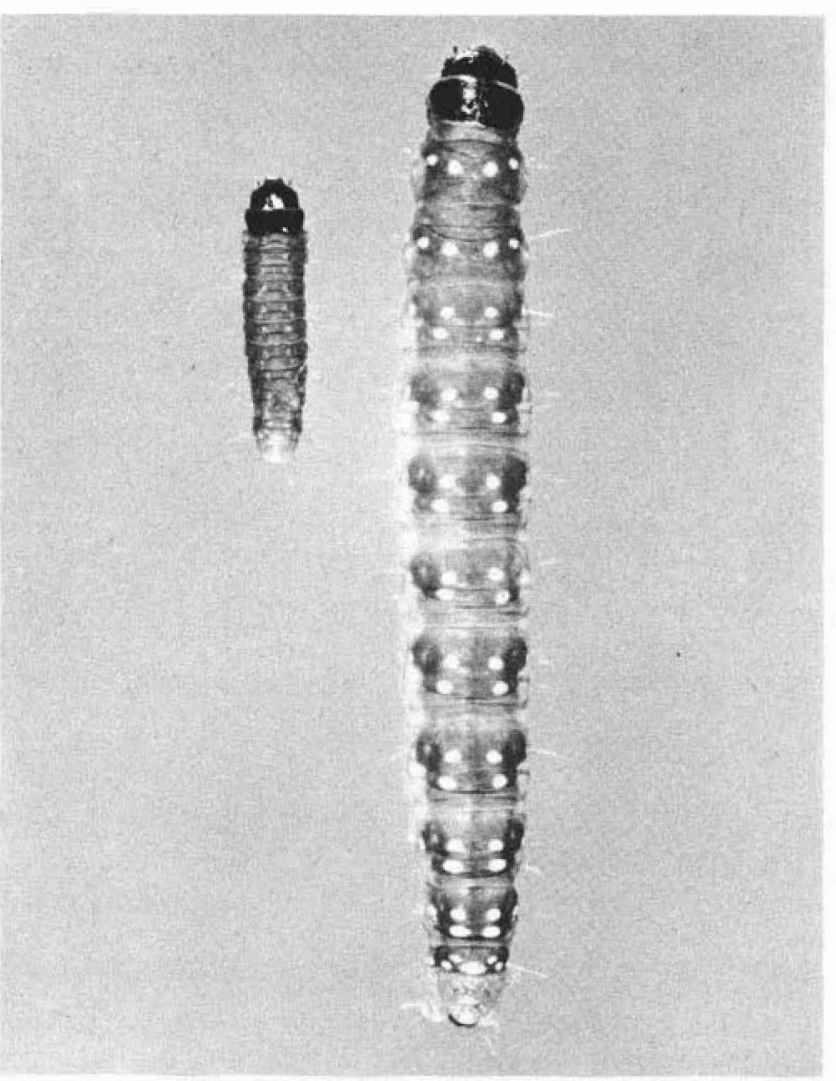

Figure 2. Effect of Bacillus thuringiensis on larval development normal larva shown on right. Photo courtesy Forest Pest Management Institute.

Many companies throughout the world now produce and formulate B.t. under a variety of trade names. B.t. products that have met all the requirements on efficacy and safety are fully registered in Canada under the Pest Control Products Act for control of spruce budworm. Three companies are presently marketing B.t. products in Canada.

Until the mid 1960's most commercial formulations were prepared from the Berliner strain of the bacterium but in North America this has been largely superceded by a more toxic strain termed HD-1 after its discoverer Howard Dulmage. Concerted field testing for spruce budworm control began in Canada about twelve years ago

\section{Mode of Action of Bacillus thuringiensis}

Once a susceptible larva ingests B.t. from contaminated foliage, the alkaline digestive juices of the insect's mid gut partly dissolve the crystal. This releases toxic proteins that can damage the cells lining the gut, causing them to swell and burst. The proteinaceous covering on the bacterial spores can also affect these cells. The gut becomes paralyzed, feeding ceases and the gut contents may spill into other body cavities of the larva. Ingested spores also germinate and multiply and larvae frequently die of septicemia within a few days. Once the insect has consumed a lethal dose of B.t. feeding usually ceases within a few hours even though the insect may not die for several days.

\section{Formulation and Application of Baclllus thuringlensis}

The bacterium is grown in deep fermenters similar to those used to produce many antibiotics. After a period of vigorous growth, spores and crystals are formed in almost equal proportions. These spores and crystals are harvested and used as the bases of all B.t. preparations. The harvested B.t. is formulated into a concentrate that must meet a number of requirements in order to be used effectively in spray mixtures. The bacterium must remain viable but in a dormant state during storage; hence additives may be required to inhibit spore germination until the formulated material is used for spraying. The concentrated suspension should mix readily with water, and the resultant mixture should not sediment before or during application. The spray should stick and spread well on the foliage, and evaporation of the carrier should be minimized during application. Additives may be required to retard possible degradation of B.t. on the foliage.

As with all spraying operations, several parameters must be carefully controlled during application. In this case the objective is to optimize ingestion of B.t. by the pest insect. For example, B.t. should be sprayed when larvae are young and are feeding because at this stage they are susceptible to B.t. and have not yet damaged much foliage. At the same time, the new shoots must have expanded sufficiently for B.t. to coat all the new foliage that may be ingested by the larvae. There must be enough spray droplets of suitable size to coat the foliage evenly and as many droplets as possible must contain sufficient B.t. to ensure that larvae will consume a lethal dose, preferably within a day of insecticide application. The dose of B.t. that will be consumed by each insect is determined by the number and vigour of larvae to be sprayed and by the volume and dosage of B.t. applied including the size and distribution of droplets deposited on the foliage. The latter depends upon the droplet spectrum emitted from the spray nozzles, and changes such as evaporation and horizontal drift that take place between emission and deposition on the foliage.

To assess the relative effectiveness of B.t. an experimental test should include an area treated with B.t., and an untreated area set aside to measure the insect survival and damage that occurs without human intervention. In both areas, budworm larval mortality and foliage protection on trees should be determined by standard methods. Assessment of foliage protection is by far the more important criterion of efficacy for the forest manager and should reflect the combined effects of $B . t$. on insect mortality and on feeding inhibition. Indeed, foliage protection can be achieved with B.t. during bud flush and shoot expansion even when no drastic increase in insect mortality is observed.

\section{Current Status of the Efficacy of Bacillus thuringiensis Against Spruce Budworm}

When evaluating any new material it is customary to compare its efficacy with that of a recognized standard which in this case would be a chemical insecticide. Such comparisons should be made with caution, however, bearing in mind that B.t. must be ingested to be effective whereas currently used chemical insecticides kill primarily on contact with the insect.

When compared to conventional chemical insecticides, B.t. has advantages and disadvantages. Its advantages lie in its specificity to a narrow spectrum of insect life which enables B.t. to supplement other natural biological control agents. Its neglible toxicity to fish, birds and mammals makes B.t. particularly well suited to use in environmentally sensitive areas, especially protected areas around permanent bodies of water and human habitation. The main disadvantages are that the 

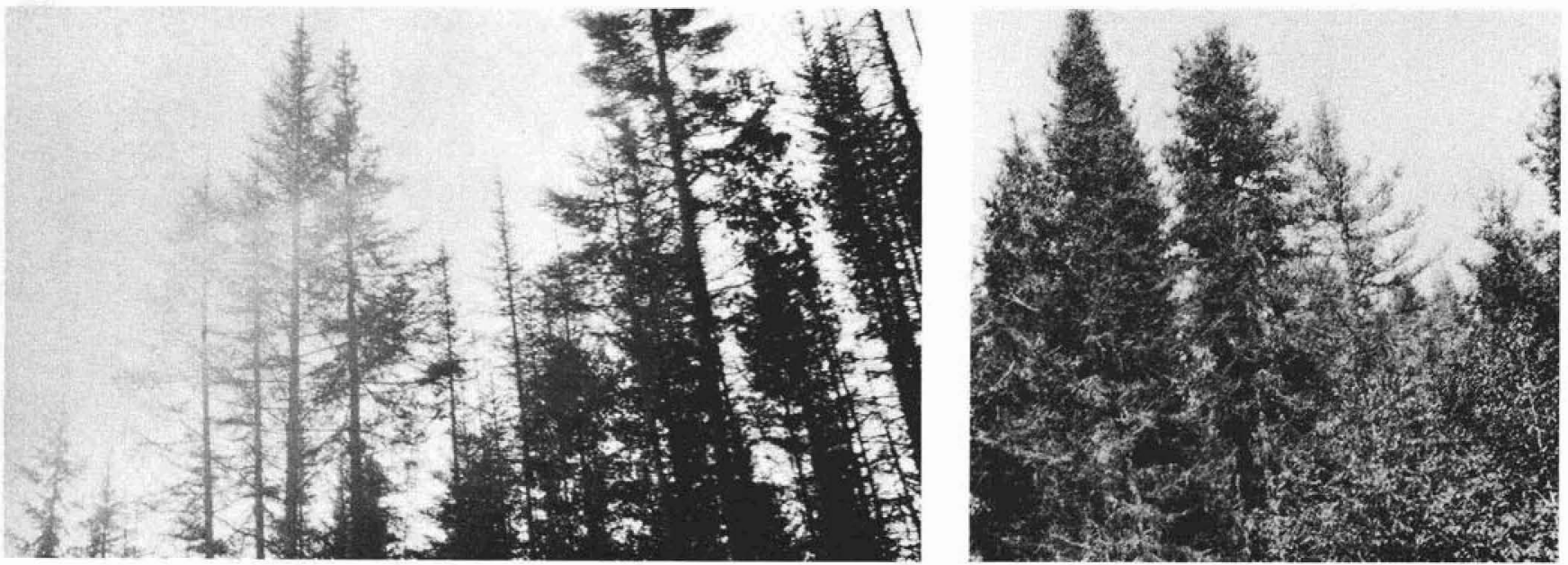

Figure 3. (a) Untreated stand. (b) Stand treated with Bacillus thuringiensis. Photos courtesy Centre de recherches forestières des Laurentides.

time period during which B.t. can be applied is shorter, and the cost of the product and of application (dictated up to now by higher applied volumes) is greater. Many of the early tests with B.t. gave inconsistent results and there was doubt until recently about the reliability of B.t. (Blais 1976). This problem largely resulted from the desire to reduce application costs before it was first clearly established that B.t. could be a reliable insecticide. Recent tests with better formulations and application techniques, and with higher dosages show: that much of the earlier work used marginal dosages under the constraints imposed by the application techniques; and that, B.t. can be comparable in efficacy to chemical insecticides when both are applied correctly (Fig. 3). The latter provision of correct application includes all aspects from suitable formulation of the product to applying the required quantity at the proper time with the correct equipment and technology.

These positive conclusions on the efficacy of B.t. are largely the result of research conducted by the Canadian Forestry Service and the US Department of Agriculture - Forest Service, and through the concerted efforts of forest managers in Quebec, Nova Scotia, Ontario, and the State of Maine. For example, in 1980, members of the Quebec Department of Energy and Resources concluded that "after 8 years of research and development with B.t. against spruce budworm, it seems that this product can be used on an operational basis in Quebec, with the same chance of success as chemical insecticides provided that some constraints relevant to the fact that $B_{+} t$. has to be ingested to work are respected" (Dorais et al. 1980). In Ontario and the Atlantic Provinces, a total of 51093 ha of forests were sprayed with B.t. in 1979 and 1980 (Smirnoff and Morris 1982). Areas where at least 50 percent of the current year's foliage remained after treatment ranged from 74 percent of the sprayed area in Ontario to 92 percent in Nova Scotia; an exception was Newfoundland where only 48 percent success was recorded due to application problems.

\section{Expected Future Developments with Bacillus thuringiensis}

B.t. is now generally accepted as an effective insecticide when applied correctly. Improvements are thus mostly directed to ensuring that the material is correctly applied and to reducing the cost of the insecticide treatment.

Correct use of B.t. encompasses a broad range of activities collectively termed "application technology" and while progress has been made there is still room for improvement. For example, questions remain to be answered on the optimum size of droplets that should be generated, on how much B.t. should be present in each droplet, and even on how deposition of droplets on needles can best be monitored to estimate the distribution and quantity of emitted material collected on foliage.

Cost reductions can be achieved in many ways and there is good reason to expect that B.t. treatments will eventually cost no more than chemical insecticide treatments.

The amount of liquid carrier affects both the transportation cost to the site of application, and the payload of active ingredient that can be carried by an aircraft. Work is in progress to formulate concentrates containing less liquid carrier and to apply diluted formulations at a rate of $2.5 \mathrm{~L} / \mathrm{ha}$, which is only half the volume of carrier liquid now normally used and is a rate comparable to two conventional applications of chemical insecticide. Results so far indicate that transportation and application costs could be reduced by more than one quarter with no loss in efficacy.

The potency of B.t. preparations can also be increased and hence the costs reduced by selecting even better strains of B.t. and by further refining the fermentation process. B.t. is produced in North America mainly for the United States agricultural market and the commercial strain of B.t. was selected for its effectiveness against the cabbage looper caterpillar. This B.t. strain is not necessarily the most potent strain for spruce budworm. Potency among strains of B.t., and susceptibility among insect species to one strain of B.t. often vary by as much as 100 -fold. Clearly a search for a B.t. strain specific for spruce budworm control offers potential improvements in efficacy. Improvements are also possible by adjusting the fermentation conditions and growth medium to find the optimal conditions for production of potent B.t. Many microbial case studies attest to these potential improvements - for example, the production of penicillin antibiotics was increased 50000 -fold by using better strains and fermentation conditions. 
Further cost reductions could result by extending the viability of B.t. on foliage so that there is more opportunity for larvae to cosume a lethal dose. The main area currently being examined is possible instability due to degradation by ultra-violet light or by phytotoxins on the foliage surface.

Finally, cost could also be reduced by adding materials to B.t. that act synergistically to increase its potency. One approach that has been used is to add traces of chitinase to the B.t. spray (Smirnoff et al. 1973). Chitinase is an enzyme that in some conditions, can act on the membrane lining the insect's gut, making it easier for B.t. to enter the insect's other body cavities.

In summary, recent experience both at the research and operational level, has demonstrated that B.t. is an effective insecticide against the spruce budworm when applied correctly. Further improvements could be made in potency of the product, in its formulation, in application rates, and in application technology. Research into these areas is being actively pursued, with the belief that B.t. can provide an effective and efficient pest control option for the forest manager.

\section{References}

Blais, J.R. 1976. Can Bacillus thuringiensis replace chemical insecticides in the control of spruce budworm? For. Chron. 52: $57-60$

Dorais, L., M. Pelletier, et W.A. Smirnoff. 1980. Pulvérisations aériennes de Bacillus thuringiensis Berliner réalisées au Québec de 1971 à 1979 contre la tordeuse des bourgeons de l'épinette, Choristoneura fumiferana (Clem.). Rapport présenté au Vlê Congrês International de l'aviation agricole à Turin, Italie.

Smirnoff, W.A., A.P. Randall, R. Martineau, W. Haliburton, and A. Juneau. 1973. Field test of the effectiveness of chitinase additive to Bacillus thuringiensis Berliner against Choristoneura fumiferana (Clem.). Can. J. For. Res. 3: 228-236

Smirnoff, W.A. and O.N. Morris. 1982. Field development of Bacillus thuringiensis for control of defoliation by the spruce budworm in eastern Canada 1970-1980. In Biological control attempts against insects and weeds in Canada 1969-1980. Commonwealth Agricultural Bureaux, Farnham Royal, U.K. (in press).

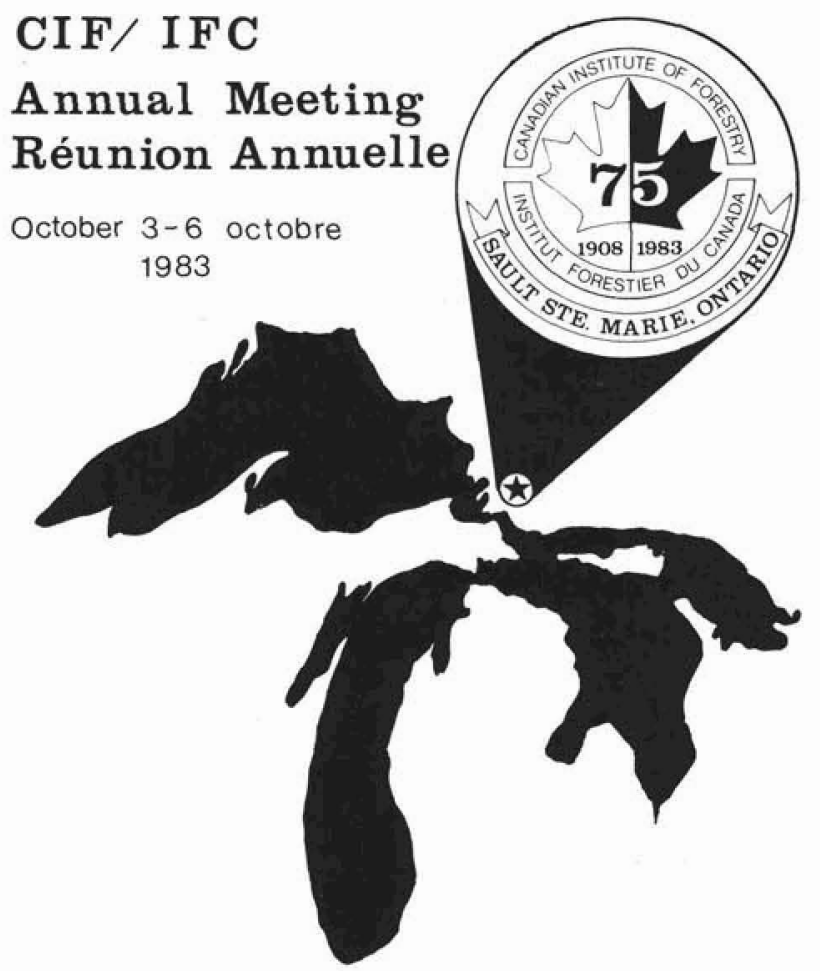

Forestry in Canada

yesterday - today - tomorrow 